\title{
Incorporação de lodo de lavanderia industrial na fabricação de tijolos cerâmicos
}

\author{
(Incorporation of industrial laundry mud in the \\ production of ceramic bricks)
}

\author{
L. C. S. Herek, A. T. Silva Junior, C. C. Pavezzi, R. Bergamasco, C. R. G. Tavares \\ CTC-DEQ, Universidade Estadual de Maringá, Av. Colombo 5790, Zona 7, Maringá, PR 87020-900 \\ luciana_csh@hotmail.com.
}

\begin{abstract}
Resumo
O lodo gerado em ETEs de lavanderias industriais é um material não inerte de Classe IIA, devido à sua solubilidade em água. Este resíduo tem recebido atenção especial devido à grande quantidade produzida e, consequentemente, ao custo demandado para destino em aterros industriais. O objetivo deste trabalho é avaliar a qualidade dos tijolos cerâmicos de vedação, fabricados com lodo de lavanderia industrial incorporado em massa cerâmica vermelha, pelo processo de extrusão, em escala de laboratório (73 x 35 x $55 \mathrm{~mm}$ ), com os seguintes percentuais de lodo de lavanderia: 0 (modelo), 5, 10, 15 e 20\% em peso. Após a queima, em indústria cerâmica, a qualidade dos tijolos foi analisada por meio de ensaios de resistência à compressão, absorção de água, lixiviação e solubilização. Nos resultados obtidos observou-se que a resistência à compressão é inversamente proporcional à quantidade de lodo adicionada, enquanto a absorção de água é diretamente proporcional à mesma quantidade de lodo adicionada na fabricação dos tijolos. No ensaio de lixiviação nenhum dos metais pesados analisados foi lixiviado; para o ensaio de solubilização nenhum dos metais analisados foi detectado, comprovando que o produto é inerte. De acordo com os resultados obtidos, é possível a fabricação de tijolos de vedação com até $20 \%$ de resíduo de lavanderias industriais incorporados em argila.

Palavras-chave: lodo de lavanderia industrial, tijolo cerâmico, argila, cerâmica vermelha, resíduos industriais.
\end{abstract}

\begin{abstract}
The sludge from wastewater treatment in industrial laundries is a II-A class non-inert material, due to its solubility in water. This waste has been paid special attention, due to the large quantities that are produced and therefore the high cost of the final destination in landfills. This way, the objective of this work was to evaluate the quality of sealing ceramic bricks manufactured with sludge from industrial laundry incorporated in red ceramic mass, by the extrusion process, in laboratory scale $(73 \times 35 \times 55 \mathrm{~mm})$, with the following weight percentages of sludge: 0 (model), 5, 10, 15, and 20\%. After the burning in a ceramic industry, the quality of the bricks was evaluated by tests of compression resistance, water absorption, leaching and solubilization. The obtained results showed that the compression resistance was inversely proportional to the quantity of sludge that was added during the manufacturing of the bricks, while water absorption was directly proportional to that quantity. None of the analyzed heavy metals was leached in the leaching test or detected in the solubilization test, proving that the product is inert. According to the results it is possible to produce sealing bricks with up to $20 \%$ of industrial laundries sludge incorporated in clay.
\end{abstract}

Keywords: industrial laundry sludge, ceramic brick, clay, red ceramics, industrial wastes.

\section{INTRODUÇÃO}

Todo processo industrial gera resíduos, muitas vezes tóxicos e perigosos, não sendo possível simplesmente descartar estes materiais na natureza sem causar danos à saúde e ao ambiente [1].

$\mathrm{O}$ processo de lavagem em lavanderias industriais utiliza grande quantidade de produtos químicos que conferem maciez, brilho, solidez e cor às peças. Os corantes utilizados na etapa de tingimento são de vários tipos: reativos, sulfurosos, diretos e pré-metalizados [2]. Estes corantes contêm em sua composição metais pesados ligados a parte orgânica da molécula. Os corantes que não se aderem à fibra durante o tingimento são descartados durante as etapas de lavagem e conferem cor ao efluente. É necessária a remoção desta cor para lançar o efluente em um corpo receptor ou para reutilizá-lo. Durante o tratamento nas ETEs são utilizados produtos químicos, como soda ou cal - para correção do pH; sulfatos de alumínio ou ferro - para coagulação e polieletrólitos catiônicos ou aniônicos - para decantação ou floculação, formando nesta etapa, o resíduo sólido conhecido como lodo. Portanto, o resíduo proveniente das ETEs de lavanderias industriais apresenta em sua composição metais pesados, que quando em contato com o solo pode causar infiltração chegando à contaminação do lençol freático. A NBR 10.004/04 [3] classifica este resíduo como sendo de Classe IIA, não inerte, sendo passível de aproveitamento. As indústrias de 
cerâmica vermelha podem ter um papel relevante como receptoras de resíduos sólidos visando sua disposição final. Esta incorporação, feita de maneira criteriosa, permite dar um destino ambientalmente correto para resíduos que, de outra forma, seriam fontes de poluição [4].

Técnicas que incorporam resíduos industriais em matrizes solidificantes reduzem a mobilidade dos poluentes destes resíduos. Como agente solidificante no tratamento de resíduos industriais a argila merece destaque, pois vem sendo utilizada em várias pesquisas com a finalidade de uso na construção civil: Lodo de ETA [5, 6]; resíduo oleoso proveniente do setor petrolífero $[4,7,8]$; lama de alto forno [9]; lama de mármore e granito [10] e lodo de indústria têxtil [11]. Borra oleosa foi incorporada na fabricação de blocos cerâmicos de vedação apresentando bons resultados com até $20 \%$ em peso de borra oleosa incorporada em argila, não comprometendo as características essenciais de qualidade dos blocos cerâmicos, e nem a saúde humana, não sendo prejudicial ao ambiente [7]. Lama de mármore e granito foi adicionada em cerâmica vermelha para a fabricação de blocos extrudados, e atingiram padrões de qualidade do produto cerâmico com até $20 \%$ em peso de lama adicionada à argila [10]. Lodo de indústria têxtil foi incorporada em argila para a preparação de corpos de prova. Os blocos foram analisados em relação a ensaios mecânicos e físicos e concluíram que é possível o uso de lodo têxtil em cerâmica vermelha [11]. A reutilização destes resíduos pode resolver, de um lado, o problema de descarte em área da estação de tratamento e, por outro lado, diminuir a quantidade de massa argilosa consumida, portanto, o custo da matéria-prima para produção da cerâmica [5]. Outra vantagem que a incorporação de resíduos industriais em cerâmica vermelha acarreta é a de não gerar outros tipos de resíduos.

Oobjetivo deste trabalho foi estudar a porcentagem ideal de incorporação de lodo de lavanderia industrial em massa argilosa. Visando um reaproveitamento deste resíduo na construção civil, fabricaram-se tijolos de vedação em escala de laboratório, avaliando as características mecânicas (resistência à compressão e absorção de água), e ambientais (lixiviação e solubilização).

\section{MATERIAIS E MÉTODOS}

\section{Matérias-primas}

- Lodo gerado na fase de tratamento primário na ETE de lavanderia industrial (Rabello e Farias Ltda.), situada na região de Maringá, PR. Trabalhou-se com lodo de uma lavanderia industrial, uma vez que este lodo não altera significativamente sua composição em relação a cada lavanderia industrial, pois num mesmo dia, podem-se utilizar todos os tipos de corantes, obtendo-se um efluente bastante variado. Este efluente é tratado com hidróxido de sódio $50 \%$ em peso, sulfato ferroso e ou de alumínio - dependendo a demanda do mercado - e polieletrólito catiônico;
- Massa argilosa industrial constituída de uma mistura de argilas, proveniente da região de Japurá, PR, utilizada para o preparo de tijolos em geral e telhas, armazenada na Cerâmica Barra Bonita, Japurá, PR.

\section{Preparação das amostras}

- Lodo: o lodo foi retirado do leito de secagem com consistência pastosa e depositado em terreiro cimentado com valas laterais para escoamento. O material foi seco ao sol por um período de $72 \mathrm{~h}$, sendo misturado de duas a três vezes por dia para uma melhor secagem; à noite o material era coberto com lona para evitar a umidade. Após esta etapa, o resíduo foi moído em moinho de barras modelo $\mathrm{n}^{\circ}$ 5, Lombard Super, até a obtenção de uma granulometria $0,6 \mathrm{~mm}$. Após a moagem o material foi homogeneizado, de forma a garantir que qualquer quantidade retirada da amostra seja representativa. A seguir o material foi armazenado em tambores com capacidade de $200 \mathrm{~L}$.

- Massa argilosa: a massa argilosa foi seca ao sol por um período de $72 \mathrm{~h}$ em terreiro cimentado. Após a secagem realizou-se a moagem até atingir uma granulometria 0,6 $\mathrm{mm}$. O material foi homogeneizado e armazenado em tambores com capacidade para $200 \mathrm{~L}$.

\section{Caracterização das amostras}

O lodo e a massa argilosa foram caracterizados com relação à presença de metais, procedendo-se da seguinte forma: retirou-se uma amostra de lodo $(10 \mathrm{~g})$ e outra de massa argilosa $(10 \mathrm{~g})$ dos tambores e realizou-se a abertura das respectivas amostras pelo método nitro-perclórico [12]. As soluções obtidas da abertura das amostras, de lodo e de massa argilosa, foram submetidas à leitura de metais por absorção atômica, em espectrofotômetro Varian Spectr AA-10 Plus. As amostras foram caracterizadas em relação à massa $(\mathrm{g} / \mathrm{kg})$. Analisaram-se os metais presentes em corantes e produtos químicos utilizados em lavanderias industriais. Retirou-se dos tambores $100 \mathrm{~g}$ de amostra de lodo e $100 \mathrm{~g}$ de amostra de massa argilosa, e estas foram submetidas a análises de lixiviação [13] e de solubilização [14]. As leituras das concentrações dos metais $(\mathrm{g} / \mathrm{mL})$ no espectrofotômetro foram realizadas com relação aos metais que foram caracterizados anteriormente em relação à massa $(\mathrm{g} / \mathrm{kg})$, e que constam das listagens $\mathrm{F}$ e $\mathrm{G}$ da NBR 10.004/04 [3]. A massa argilosa também foi caracterizada de acordo com as Normas do DNER e da ABNT:

Umidade natural: foi utilizado o método gravimétrico com a secagem em estufa, segundo o procedimento descrito na norma [15]; massa específica: utilizou-se o método de ensaio segundo a NBR 6508/84 [16]; ensaio de granulometria: primeiramente a massa argilosa foi seca em estufa por $24 \mathrm{~h}$; em seguida foi destorroada e peneirada para a fração < 40 mesh $(425 \mu \mathrm{m})$, e então foi utilizado o procedimento da norma [17]; limite de liquidez (LL), foi adotada a NBR 6459/84 [18]; limite de plasticidade (LP), foi adotada a NBR 7180/84 [19]; índice de plasticidade (IP), 
com os dois valores obtidos (LL e LP), que representam teores de umidade, foi determinado o IP simplesmente pela diferença aritmética entre o LL e o LP.

\section{Fabricação dos tijolos de vedação}

Para se estudar a porcentagem ideal de incorporação de lodo em massa argilosa, foram fabricados tijolos de vedação, em escala de laboratório, com dimensões de (73 x $35 \times 55 \mathrm{~mm})$ (comprimento x largura $\times$ altura), em maromba Gelenski Ltda. MVIG-05 647. Os tijolos foram fabricados nas proporções de $0,5,10,15$ e $20 \%$ em peso de lodo em relação à massa argilosa. Para cada ensaio foram utilizados $15 \mathrm{~kg}$ de material (levando-se em conta o lodo e a massa argilosa). Para cada ensaio, os materiais secos eram pesados (perfazendo um total de $15 \mathrm{~kg}$ ), homogeneizados e umedecidos com água. Foram utilizados em torno de $5 \mathrm{~L}$ de água (de abastecimento urbano) para cada ensaio; ao se aumentar a quantidade de lodo adicionada à massa argilosa uma quantidade menor de água era necessária para que fosse umedecido o material (em torno de $200 \mathrm{~mL}$ ). Esta liga foi obtida manualmente e adicionada ao bocal da maromba. A quantidade de água adicionada à mistura era o suficiente para facilitar a homogeneização. Os tijolos foram moldados com pastas consistentes pelo processo de extrusão, após passar pela câmara de vácuo para a retirada do ar presente na mistura. Depois de moldados, os tijolos foram secos naturalmente em ambiente sem incidência de sol ou vento até o ponto de queima, evitando o aparecimento de trincas. Para a queima os tijolos foram transportados até a Cerâmica Barra Bonita, Japurá, PR, onde foram queimados em fornos intermitentes tipo chama reversível (consiste em uma abóboda fechada e piso de tijolos perfurados de modo a permitir a passagem dos gases de combustão para os dutos de tiragem). Os tijolos ficam no interior deste forno por um período de $24 \mathrm{~h}$ até $100{ }^{\circ} \mathrm{C}$, onde ocorre a retirada da água presente nos tijolos, e após são queimados por três dias até atingir uma temperatura em torno de $900{ }^{\circ} \mathrm{C}$, onde se atinge a sinterização. A temperatura do forno é aumentada a cada $24 \mathrm{~h}$.

\section{Avaliação dos tijolos após a queima}

Os tijolos de vedação foram avaliados em relação a ensaios mecânicos e ambientais:

- Nos ensaios mecânicos, realizaram-se testes de resistência à compressão de acordo com o método de ensaio descrito na norma [20], em prensa (Fábrica de Artefatos de Metais Irmãos Trevisan Ltda.) para bloco cerâmico de vedação com Aro 109-4000, e absorção de água, segundo método de ensaio descrito na norma [20].

- Nos ensaios ambientais realizaram-se testes de lixiviação de resíduos, norma NBR 10.005/04 e solubilização de resíduos de acordo com a norma [14], com leitura das amostras realizadas no espectrofotômetro de absorção atômica.

\section{RESULTADOS E DISCUSSÃO}

\section{Caracterização das amostras}

A Tabela I apresenta os metais analisados na amostra de lodo e argila em relação à massa.

Tabela I - Metais nas amostras de resíduo e massa argilosa. [Table I - Metals in the waste and clay mass samples.]

\begin{tabular}{ccc}
\hline Metais & $\begin{array}{c}\text { Massa Argilosa } \\
(\mathrm{g} / \mathrm{kg})\end{array}$ & $\begin{array}{c}\text { Resíduo } \\
(\mathrm{g} / \mathrm{kg})\end{array}$ \\
\hline $\mathrm{Al}$ & 1,99 & 15,9 \\
$\mathrm{Cd}$ & - & - \\
$\mathrm{Pb}$ & - & - \\
$\mathrm{Cu}$ & 0,03 & 0,05 \\
$\mathrm{Fe}$ & 13,5 & 16 \\
$\mathrm{Ni}$ & - & 0,01 \\
$\mathrm{Hg}$ & - & - \\
$\mathrm{Zn}$ & 0,01 & 0,07 \\
$\mathrm{Cr}$ & 0,02 & 0,01 \\
$\mathrm{Mn}$ & 0,01 & 0,04 \\
$\mathrm{Ca}$ & 5,7 & 9,8 \\
$\mathrm{Mg}$ & 1,15 & 2,08 \\
$\mathrm{~K}$ & 2,6 & 1,2 \\
$\mathrm{Co}$ & - & - \\
$\mathrm{Na}$ & 0,04 & 0,3 \\
$\mathrm{Ba}$ & 9,50 & 5,4 \\
\hline
\end{tabular}

O lodo analisado apresentou altos teores de alumínio e ferro. Estes elementos são constituintes de produtos utilizados durante o processo de tratamento do efluente sendo retidos no resíduo. O ferro também é encontrado na massa argilosa, pois é natural de solos argilosos. Os elementos $\mathrm{Ca}$ e Mg são encontrados na dureza da água da região e não são prejudiciais ao ambiente. Os teores de $\mathrm{Zn}, \mathrm{Cr}, \mathrm{Cu}$ e $\mathrm{Ni}$ provavelmente são derivados dos corantes utilizados durante o processo de tingimento. A massa argilosa possui traços de $\mathrm{Cu}, \mathrm{Zn}, \mathrm{Cr}, \mathrm{Mn}$ e Co. Em geral, as argilas encontramse associadas a estes metais formando quartzo, pirita, mica, calcita, dolomita, entre outros.

Tabela II - Concentração do extrato lixiviado do resíduo. [Table II - Concentration of the extract from the lixiviation test performed on the waste.]

\begin{tabular}{ccc}
\hline Metais & $\begin{array}{c}\text { Resíduo } \\
(\mathrm{mg} / \mathrm{L})\end{array}$ & $\begin{array}{c}\text { Limite - } \\
\text { Anexo F: NBR } \\
10.004 / 04(\mathrm{mg} / \mathrm{L})\end{array}$ \\
\hline $\mathrm{Ba}$ & 0,06 & 70 \\
$\mathrm{Cr}$ & - & 5 \\
\hline
\end{tabular}


Para a amostra de lodo de lavanderia foram realizados os ensaios de lixiviação [13] e solubilização [14], Tabelas II e III [21], respectivamente, onde foram analisados os metais de acordo com as listagens dos anexos $\mathrm{F}$ (normativo para extrato lixiviado) e $\mathrm{G}$ (normativo para extrato solubilizado) da [3] NBR 10.004/04, presentes na Tabela I. Na Tabela III observa-se que os metais $\mathrm{Fe}$ e $\mathrm{Al}$, excederam o valor máximo permitido pela listagem do Anexo G da norma [3].

Tabela III - Concentração do extrato solubilizado do resíduo.

[Table III - Concentration of the extractfrom the solubilization of the waste.]

\begin{tabular}{ccc}
\hline Metais & $\begin{array}{c}\text { Resíduo } \\
(\mathrm{mg} / \mathrm{L})\end{array}$ & $\begin{array}{c}\text { Limite }- \text { Anexo G: NBR } \\
10.004 / 04(\mathrm{mg} / \mathrm{L})\end{array}$ \\
\hline $\mathrm{Al}$ & 0,6 & 0,2 \\
$\mathrm{Cu}$ & - & 2 \\
$\mathrm{Cr}$ & - & 0,05 \\
$\mathrm{Fe}$ & 0,5 & 0,3 \\
$\mathrm{Mn}$ & - & 0,1 \\
$\mathrm{Na}$ & 0,2 & 200 \\
$\mathrm{Zn}$ & - & 5 \\
$\mathrm{Ba}$ & 0,01 & 0,7 \\
\hline
\end{tabular}

A Tabela IV mostra as diferentes frações de materiais presentes na massa argilosa. De acordo com os resultados obtidos a massa argilosa é de boa qualidade para uso em produtos cerâmicos, pois apresenta quantidades significativas de materiais argilosos (49\%), com partículas abaixo de 2 $\mathrm{mm}$. Este tamanho de partícula corresponde à fração argila em algumas escalas internacionais para classificação de solos [22].

Tabela IV - Teores das diferentes frações presentes na massa argilosa obtida pela análise granulométrica.

[Table IV - Composition of the clay mass obtained by granulometric analysis.]

\begin{tabular}{cccc}
\hline Amostra & $\begin{array}{c}\text { Areias (\%) } \\
0,06<x \leq 0,6 \mathrm{~mm}\end{array}$ & $\begin{array}{c}\text { Silte (\%) } \\
0,002 \leq \mathrm{x} \leq 0,06 \mathrm{~mm}\end{array}$ & $\begin{array}{c}\text { Argila (\%) } \\
<0,002 \mathrm{~mm}\end{array}$ \\
\hline $\begin{array}{c}\text { Massa } \\
\text { argilosa }\end{array}$ & 24 & 27 & 49 \\
\hline
\end{tabular}

É a fração argila que fornece a plasticidade necessária para tornar o material trabalhável e moldável, sendo fator importante para o processo de extrusão. Para que o material forneça bons produtos cerâmicos é necessária a presença de silte e de argila, materiais não plásticos. O conteúdo de silte presente na massa argilosa é da ordem de $27 \%$, enquanto que a quantidade de areia é de $24 \%$, estes materiais são responsáveis pela menor plasticidade da massa argilosa e retração durante o processo de fabricação.

A Tabela $\mathrm{V}$ apresenta os ensaios físicos realizados para a caracterização da argila, uma vez que esta possui uma quantidade significativa de partículas finas.

Tabela $\mathrm{V}$ - Índices físicos para a massa argilosa. [Table $V$ - Physical indexes of the clay mass.]

\begin{tabular}{cc}
\hline Índices Físicos & Teor (\%) \\
\hline LP & 20 \\
LL & 50 \\
IP & 30 \\
U & 3,22 \\
\hline
\end{tabular}

O LP, 20\%, está dentro da faixa recomendada para materiais argilosos $(18 \leq \mathrm{LP} \leq 30)$, isso ajudará na secagem e menor retração do material cerâmico obtido. O IP $(10 \leq$ IP $\leq$ $35)$ encontrado está dentro da faixa para materiais argilosos. Este valor, $30 \%$, indica uma alta compressibilidade. De acordo com os resultados obtidos deve-se adicionar de 20 a $50 \%$ de água à massa cerâmica, para torná-la trabalhável.

Os tijolos de vedação fabricados com incorporação de lodo de lavanderia foram avaliados com relação às seguintes análises:

- Resistência à compressão

A Fig. 1 mostra o ensaio de resistência à compressão realizado nos tijolos de vedação fabricados com incorporação de lodo de lavanderia industrial com 0, 5, 10, 15 e $20 \%$ em peso. É possível observar um decréscimo da resistência com o aumento da porcentagem de lodo incorporado à massa argilosa.

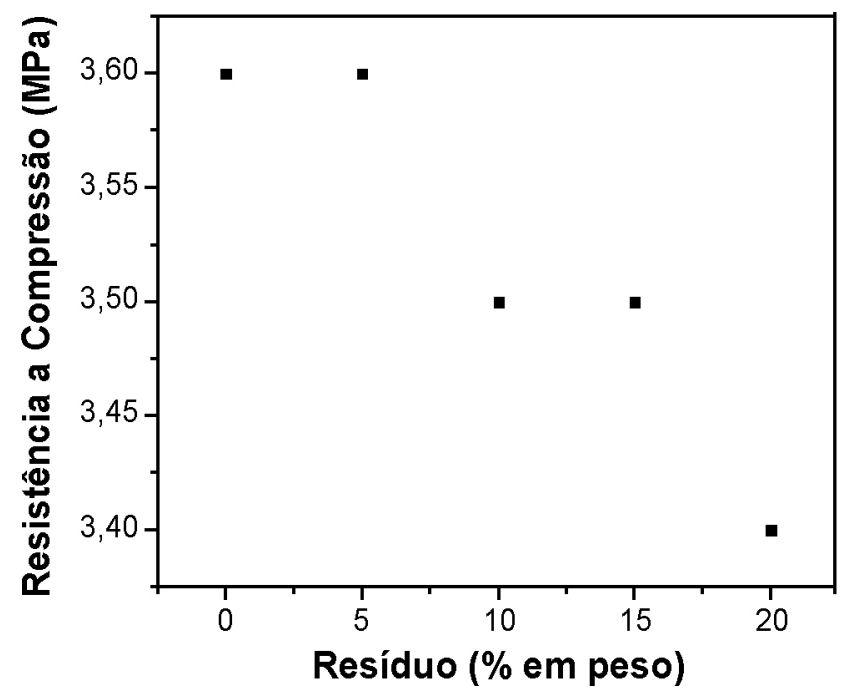

Figura 1: Resistência à compressão (MPa) em função dos teores de resíduo incorporado em peso\%.

[Figure 1: Compression resistance (MPa) as a function of the incorporated waste content (wt.\%).] 
Tabela VI - Concentração do extrato lixiviado nos tijolos de vedação. [Table VI-Concentration of the extract from the leaching test performed on the bricks.]

\begin{tabular}{ccccccc}
\hline & \multicolumn{5}{c}{ Extrato lixiviado (mg/L) } & \multirow{2}{*}{$\begin{array}{c}\text { Limite - Anexo F: NBR } \\
10.004 / 04(\mathrm{mg} / \mathrm{L})\end{array}$} \\
\cline { 2 - 6 } Metais (mg/L) & $0 \%$ & $5 \%$ & $10 \%$ & $15 \%$ & $20 \%$ & 70 \\
$\mathrm{n}$ & - & - & - & - & - & 5 \\
$\mathrm{Cr}$ & - & - & - & - & - & 5 \\
\hline
\end{tabular}

Tabela VII - Concentração do extrato solubilizado nos tijolos de vedação.

[Table VII - Concentration of the extract from the solubilization test performed on the bricks.]

\begin{tabular}{ccccccc}
\hline \multirow{2}{*}{ Metais $(\mathrm{mg} / \mathrm{L})$} & \multicolumn{5}{c}{ Extrato solubilizado (mg/L) } & $\begin{array}{c}\text { Limite }- \text { Anexo G: NBR } \\
10.004 / 04(\mathrm{mg} / \mathrm{L})\end{array}$ \\
\cline { 2 - 6 } & $0 \%$ & $5 \%$ & $10 \%$ & $15 \%$ & $20 \%$ & 0,2 \\
$\mathrm{nl}$ & - & - & - & - & - & 0,05 \\
$\mathrm{Cr}$ & - & - & - & - & - & 2 \\
$\mathrm{Cu}$ & - & - & - & - & - & 0,3 \\
$\mathrm{Fe}$ & - & - & - & - & - & 0,1 \\
$\mathrm{Mn}$ & - & - & - & - & - & 200 \\
$\mathrm{Na}$ & - & - & - & - & - & 5 \\
$\mathrm{Zn}$ & - & - & - & - & - & 0,7 \\
$\mathrm{Ba}$ & - & - & - & - & - & \\
\hline
\end{tabular}

Com a incorporação de 5\% de lodo não houve variação na resistência, pois a quantidade de lodo adicionada não influencia nas propriedades da queima. Ao se adicionar $10 \%$ de lodo, a resistência sofre uma diminuição de $10 \%$ (3,5 MPa), em relação aos tijolos fabricados sem a presença de lodo, e mantém-se praticamente constante quando se adiciona $15 \%$ de lodo, com uma variação desprezível. Com um teor de $20 \%$ de lodo incorporado a resistência diminui $20 \%$ em relação aos tijolos fabricados sem lodo. Constatouse que a quantidade de lodo adicionada não é diretamente proporcional à diminuição da resistência. Mesmo a resistência tendo apresentado uma diminuição de acordo com o aumento do teor de lodo para a fabricação dos tijolos os mesmos encontram-se dentro dos valores estabelecidos para blocos cerâmicos de vedação [23].

- Absorção de Água: no ensaio de absorção de água foram avaliados os tijolos fabricados em escala de laboratório contendo $0,5,10,15$ e $20 \%$ de lodo em relação à massa argilosa. Ao contrário do que foi observado no ensaio de resistência à compressão, no ensaio de absorção de água, Fig. 2, a absorção é diretamente proporcional à quantidade de lodo incorporado para a fabricação dos tijolos. Os tijolos fabricados com 5\% de lodo apresentaram um aumento de $20 \%$ na absorção de água em relação aos tijolos fabricados somente com argila; já para os tijolos contendo $20 \%$ de lodo este aumento foi de $100 \%$. Ao se adicionar lodo de lavanderia à massa argilosa, a porosidade aumenta, uma vez que a matéria orgânica existente no lodo resulta no desprendimento de gases, e que após o aumento de temperatura durante a queima desprende-se causando o aumento dos poros [11].
Há também a presença de fibras têxteis, que ao receberem água aumentam de tamanho causando os poros. A presença destes poros facilita a entrada de água, aumentando assim a absorção. Portanto, quanto maior a quantidade de lodo adicionada maior será a absorção de água que o material irá absorver. Apesar de a absorção de água ter aumentado com o aumento da adição de lodo à massa argilosa para a fabricação dos tijolos, com $20 \%$ de lodo ainda tem-se valores de absorção dentro daqueles estabelecidos pela NBR 15270$2 / 2005$ [23], que varia entre 8 a $22 \%$.

- Lixiviação: a avaliação do grau de mobilização dos constituintes presentes no lodo incorporado a massa argilosa para a fabricação de tijolos foi verificada por meio das análises de lixiviação, conforme NBR 10.005/04 [13]. Os resultados obtidos estão na Tabela VI.

A análise de massa nas amostras de lodo e argila (Tabela I) indicou a presença dos seguintes metais tanto no lodo quanto na argila: alumínio, cobre, ferro, zinco, cromo, manganês, cálcio, magnésio, potássio, sódio e bário. Destes metais apenas bário e cromo constam na listagem F da NBR 10.004/04 [3], para lixiviação de resíduos; portanto, apenas estes foram analisados no teste de lixiviação. Na Tabela VII verifica-se que bário e cromo não estão presentes na amostra após o ensaio de lixiviação, indicando que os metais presentes no lodo ficaram indisponibilizados no tijolo cerâmico, ou seja, não foram lixiviados após a queima dos blocos. Durante a queima ocorrem reações químicas provocadas pelo aumento de temperatura no interior do forno, isso faz com que os metais presentes no material formem uma estrutura cristalina resistente. Os tijolos fabricados com incorporação 
de lodo de lavanderia em massa argilosa são classificados como não perigosos, de acordo com a NBR 10.004/04 [3], e não oferece riscos à saúde de seus usuários e ao ambiente.

- Solubilização: mesmo os tijolos cerâmicos tendo sido classificados como não perigosos em relação ao teste de lixiviação é necessária a realização do ensaio de solubilização, de acordo com a norma NBR 10.006/04 [14] para a verificação de os constituintes presentes nos tijolos serem inertes ou não. Na Tabela VII constam os metais analisados no ensaio de solubilização de acordo com a Listagem G da norma NBR 10.004/04 [3] e que foram detectados na análise de massa (Tabela I). A análise de massa nas amostras de lodo e argila (Tabela I) indicou a presença dos seguintes metais tanto no lodo quanto na argila: alumínio, cobre, ferro, zinco, cromo, manganês, cálcio, magnésio, potássio, sódio e bário. Destes metais apenas o manganês não consta na listagem $G$ da NBR 10.004/04 [3], para solubilização de resíduos; portanto, manganês não foi analisado no ensaio de solubilização.

De acordo com a Tabela III, os metais alumínio e ferro haviam sido solubilizados na amostra do lodo de lavanderia, excedendo o valor máximo permitido pela Listagem $\mathrm{G}$ da norma NBR 10.004/04 [3]; porém, os tijolos fabricados com incorporação de lodo de lavanderia não apresentaram metais solubilizados, Tabela VII, sendo classificados como não inertes.

\section{CONCLUSÕES}

Os ensaios mecânicos realizados nos tijolos de vedação fabricados com incorporação de lodo de lavanderia com teores variando de 0 a $20 \%$ em peso comprovam que a resistência mecânica é inversamente proporcional ao teor de lodo incorporado, enquanto a absorção de água é diretamente proporcional ao teor de lodo incorporado. As análises ambientais comprovam que não há lixiviação de metais nos tijolos fabricados com até $20 \%$ de incorporação de lodo; e de acordo com o ensaio de solubilização os tijolos são classificados como inertes, ou seja, nenhum dos constituintes presentes nas amostras brutas foi solubilizado. Portanto, os tijolos fabricados com incorporação de lodo de lavanderia em massa argilosa com teor de lodo de até $20 \%$ possuem estabilidade química. Assim sendo, é possível a fabricação de tijolos de vedação com lodo de lavanderia industrial incorporado em massa argilosa com teor de lodo incorporado de até $20 \%$ em peso, não afetando suas características mecânicas e ambientais.

\section{REFERÊNCIAS}

[1] K. W. Milanez, C. T. Kniess, A. M. Bernadin, H. G.
Riella, N. C. Kuhnen, Cerâmica 51, 318 (2005) 107.

[2] R. G. Twardokus, Reuso de água no processo de tingimento da indústria têxtil, Diss. Mestrado, Universidade Federal de Santa Catarina, Florianópolis, SC (2004) 73.

[3] NBR 10.004 - Resíduos Sólidos - Classificação, Rio de Janeiro (2004).

[4] C. M. F. Vieira, S. N. Monteiro, Matéria 11, 3 (2006) 217.

[5] I. C. C. Paixão, H. N. Yoshimura, D. C. R. Espinosa, J. A. S. Tenório, Cerâmica 54, 329 (2008) 63.

[6] E. M. S. Oliveira, S. Q. Machado, J. N. F. Holanda, Cerâmica 50, 316 (2004) 337.

[7] M. R. F. V. Alves, F. S. R. Holanda, Cerâmica Industrial 10, 3 (2005) 41.

[8] R. S. Santos, G. P. Souza, J. N. F. Holanda, Cerâmica 48, 307 (2002) 115.

[9] C. M. F. Vieira, C. A. C. M. Dias, A. V. Mothé, R. Sánchez, S. N. Monteiro, Cerâmica 53, 328 (2007) 381.

[10] J. B. Silva, D. Hotza, A. M. Segadães, W. Acchar, Cerâmica 51, 320 (2005) 325.

[11] A. H. Moreira, R. M. Oliveira, P. D. S. Lima, Cerâmica 47, 303 (2001) 158.

[12] E. Malavolta, G. C. Vitte, S. A. Oliveira, Avaliação do estado nutricional das plantas - princípio e aplicação, $2^{\text {a }}$ Ed., Piracicaba, SP (1997).

[13] NBR 10.005 - Lixiviação de resíduos - Procedimento, Rio de Janeiro (2004).

[14] NBR 10.006 - Solubilização de resíduos Procedimento, Rio de Janeiro (2004).

[15] Norma 213/94 - Solos - Determinação do teor de umidade do DNER (1994).

[16] NBR 6508/84 - Determinação da massa específica (1984).

[17] NBR 7181/84 - Solo - Análise granulométrica (1984).

[18] NBR 6459/84 - Solo - Determinação do limite de liquidez (1984).

[19] NBR 7180/84 Solo - Determinação do limite de plasticidade (1984).

[20] NBR 15.270-3/05 - Componentes cerâmicos. Parte 3: Blocos cerâmicos para alvenaria estrutural e de vedação Métodos de ensaio (2005).

[21] L. C. S. Herek, R. Bergamasco, C. R. G. Tavares, R. C. Friozi, E. N. J. Júnior, Anais do XVII Congresso Brasileiro de Engenharia Química, Recife (2008) 316.

[22] P. S. Santos, Ciência e tecnologia das argilas, $2^{a}$ Ed., Edgard Blucher Ltda., S. Paulo, SP (1989) 175.

[23] NBR 15.270-2/05 - Componentes cerâmicos. Parte 3: Blocos cerâmicos para alvenaria estrutural e de vedação Terminologia e requisitos (2005).

(Rec.05/06/2008, Rev. 07/10/2008, Ac. 08/02/2009) 